\title{
Power and Politics in New Service Development: An Insider Action Research Study
}

\author{
Katrin Dreyer-Gibney ${ }^{1}$ (D) David Coghlan ${ }^{1}$ (D) Paul Coughlan ${ }^{1}$ (D)
}

Accepted: 18 May 2021 / Published online: 9 June 2021

(c) The Author(s) 2021

\begin{abstract}
This paper examines power dynamics and political challenges which an insider action researcher without line authority or formal power encountered while leading cross-functional New Service Development (NSD) initiatives in a traditional, publicly funded university. NSD, as any development activity, faces competing interests in organisations and often power dynamics and political tactics which may impede service actors' development endeavours. The paper describes and reflects on how an insider action researcher together with service staff, managers and directors, conducted several different types of NSD initiatives. The paper draws on insider action research (IAR) principles, which engage theory with practice, and action with reflection. The study was carried out over an extended time period of almost three years. The paper concludes with a framework for addressing power dynamics and political action, identifying tactics available to service development actors when engaging in NSD.
\end{abstract}

Keywords Political tactics · Power \& organisational politics · Publicly funded university · New service development $\cdot$ Insider action research $\cdot$ Uncertainty exploitation

\section{Introduction}

This paper examines how power and political activity influence the development of new services in the context of a traditional, publicly funded university. There is widespread recognition that the once stable environment in which publicly funded universities have operated is rapidly changing to an uncertain one, characterised by financial constraints, globalisation, and state-imposed restrictions. To address these challenges, universities are exploring new service development (NSD) initiatives in the non-academic domain. The initiatives may be aimed at generating non-exchequer income or enhancing administrative practices. These kinds of initiative challenge existing academic power structures, established in response to earlier and different policy priorities (Richards 2006). Herein lies the challenge to management practice in the university but with an associated research opportunity. Proposed new service concepts and changes to existing services may give rise to opposition and resistance. Power dynamics and political activity may emerge when actors

Katrin Dreyer-Gibney

dreyergk@tcd.ie

1 Trinity Business School, Trinity College Dublin, the University of Dublin, Dublin, Ireland 
engage in developing new services or attempting to change existing ones. The results may be damaging to the initiatives if not to the universities. In order for managers and researchers to be better prepared for these emergent challenges, we explore the following research questions:

How do power and politics impact the development of new services in the publicly funded university; and, what political tactics may be applied by NSD actors to secure the development of new services?

The paper addresses these questions and is structured as follows: first, it introduces power and politics in NSD. Second, it describes the research framework and outlines the insider action research methodology adopted. Third, it describes the NSD initiatives carried out in a specific university setting and the associated results. Finally, it discusses and reflects upon these insights leading to concluding thoughts.

\section{The Role of Power and Politics in New Service Development}

The new service development (NSD) process is described as a set of interconnected tasks, actions and assessments, spanning from idea generation to launch or implementation (Johnson et al. 2000; Santos and Spring 2013). NSD involves multifunctional and cross-disciplinary interactions such as customer management, technical support, human resources and marketing (den Hertog et al. 2010). NSD and innovation scholars (e.g. Smith and Fischbacher-Smith 2005; Börjesson and Elmquist 2011) recognise that power and politics have a role to play the NSD process. As any development activity, NSD is likely to encounter competing interests in organisations and often power dynamics and political tactics impede service actors' development endeavours. In the corporate ecosystem, power resides largely with the executive team and cascades down. However, as Denneen and Dretler (2012) observe, creating change in a university setting is harder than creating change in a corporate setting. In academia, power usually emanates from schools and faculties, where shared governance, combined with academic freedom and tenure, provide a setting in which significant change cannot be externally mandated. In the next sections we review relevant literature in this regard.

\section{Power}

Management scholars, for example Mintzberg (1989), Pfeffer (1992), Buchanan and Badham (2008) and Hartley et al. (2015) recognise that power dynamics and political behaviour are a reality in organisations. While these may be controversial subjects, scholars acknowledge that power structures and dynamics influence organisational change processes which include service development and improvement.

Mintzberg (1989) provides examples such as workplace alliances, power blocs and competing interests that affect the way work happens. In the context of the higher education sector, Davies (2001) acknowledges the formal and informal nature of power. He names examples such as the coercive nature of power execution, based on the exercise of authority and control through threats, sanctions, withholding of funds, changing organisational structures, the removal and installation of key personnel, and resource re-allocation. More informal power applications mentioned are the encouragement of a positively supporting climate and persuasive approaches. 
While there is no unified definition of power, there are many definitions for power in the context of organisational change. Pfeffer (1992) defines power as "the potential ability to influence behaviour, to change the course of events, to overcome resistance, and to get people to do things that they would not otherwise do". Buchanan and Badham (2008) list a variety of power definitions from different authors, for example "power is the ability to get people to do what you want them to do (p 11)" and quintessentially they refer to power as the possession of authority and influence over others. In the context of service development Santos and Spring (2013) refer to Van de Ven and Poole (1995) and define power as a means to change the status quo.

In addition, there are sources of power (Pfeffer 1992; Buchanan and Badham 2008). In the context of operations management, Papke Shields and Malhotra (2008) identified four sources power in manufacturing firms - position, expertise, resource, and political. Baines et al. (2017) analysed the preconditions for service transformation. They found several factors such as organisational structure, corporate culture, power and leadership, political characteristics and strategic directions.

In summary, there is evidence of diverse definitions of power. However, there is agreement that there are recognisable sources of power, formal and informal in nature, and that individuals in organisations have personal attributes that are seen as sources of power such as stamina, resilience and the willingness to engage in conflict.

\section{Politics}

According to authors such as Buchanan and Badham (2008), having the sources and basis of power is not enough. Individuals in an organisation must have the ability to implement change. This is echoed by authors such as Pfeffer (1992) who sees the ability to implement and manage the consequences of decisions made as a critical indicator of power. He defines politics as processes and actions and behaviours through which potential power is utilised and realised. Similarly, Allen et al. (1979) see organisation politics as an act of influence, to enhance and protect the self-interest of individuals or groups.

Although organisational politics can be seen as self-serving behaviour, a growing body of research shows it can have a constructive influence (Hartley et al. 2015; Ferris et al. 2007). Ferris et al. (2007) for example state that the competing stakeholder interests need not result in destructive conflict, but can be a source of innovation, if effectively managed. Dealing with organisational politics in the workplace involves developing and using what is often known respectfully as 'political skill'. Such skill enables organisational actors to recognise, understand and mediate conflicting interests and build constructive coalitions when seeking to implement change and innovate. Ferris et al. (2007) describe political skill as a person's “....ability to effectively understand others at work, and use such knowledge to influence others to act in ways that enhances one's personal and/or organizational objectives."

In summary and for the purpose of this study we amalgamate the views of Pfeffer (1992) and Buchanan and Badham (2008) to define "politics" as the practical exercise of power in action, applying a range of techniques and tactics to secure resources, time and support in order to fulfil a mission.

While scholars agree that NSD poses many challenges, with power and politics as important aspects (Börjesson and Elmquist 2011), they suggest that research is needed to understand the ways in which NSD actors from different backgrounds and with differing interests influence NSD (Smith and Fischbacher-Smith 2005) and what tactics may 
have to be applied to realise new and improved services. This insider research study aims to address this challenge.

\section{Research Framework and Design}

This section describes the research framework and research methodology. Resulting from the literature review and initial empirical work undertaken during the first NSD initiative (Café) we drafted a research framework which is developed further during the entire research.

In the framework (Fig. 1), the central process is NSD. Throughout the process, the execution and progress may be impacted by power and politics originating from university stakeholders sceptical of an NSD initiative. In response (or, in anticipation) NSD actors, tasked with the development, may apply political tactics to ensure the implementation of the new service for which they share responsibility.

\section{Research Design}

This section outlines the research methodology, the research context, the selection of initiatives to investigate the research questions, data generation, collection and analysis, and quality criteria.

The nature of the research question is open to data emerging because of an intervention and, so, it may not be possible to predict what might take place. In this scenario an approach such as action research may produce a deeper understanding of emerging phenomena and contingent emerging factors. Action research in operations management can be used for theory building (Coughlan and Coghlan 2002), such as identifying and describing key variables, identifying linkages between variables and identifying why these relationships exist. In brief, the empirical work underpinning the paper was based on insider action research in a publicly funded university. Working with staff and her colleagues, one of the authors was in a role where, as an insider, she could engage collaboratively in the research. The empirical work involved seven NSD initiatives concerned with development of a range of service types. The research design is depicted in Fig. 2.

Formal and informal power dynamics and politics impacting New Service Development

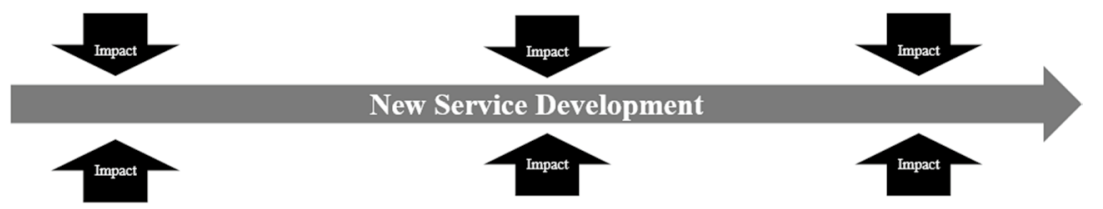

NSD Actors applying political tactics to secure the development of New Services

Fig. 1 The initial research framework 


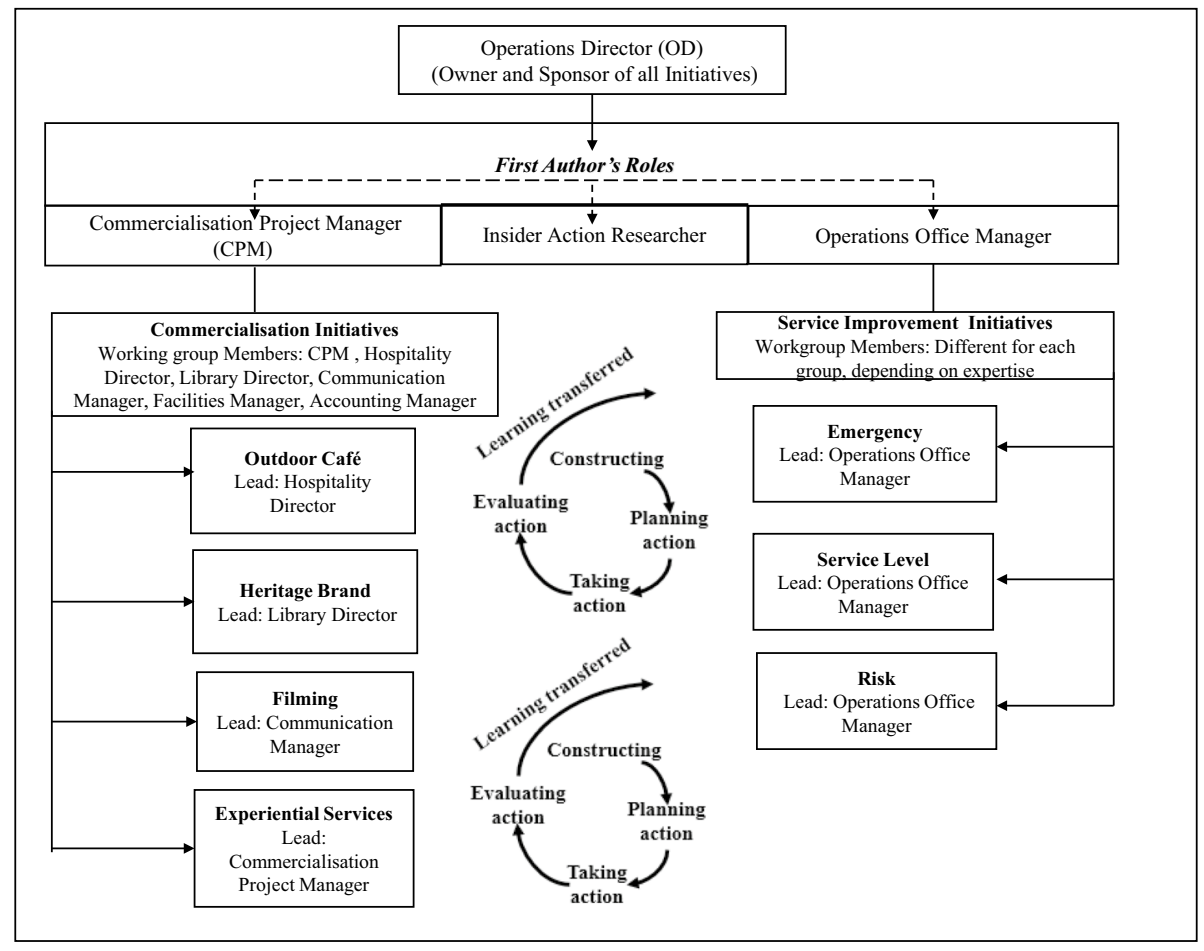

Fig. 2 The research design

\section{Insider Action Research}

As Coghlan (2001) observes, managers are increasingly undertaking action research projects in their own organisations. Insider action research (IAR) is a type of action research whereby a researcher is a member of the organisation and intends to remain a member of the organisation after the research work has been completed. It involves opportunistically planned interventions in real time situations and a study of those interventions as they occur, which in turn informs further interventions. Working with the epistemological assumption that the purpose of academic research is not just to describe, understand and explain the world but also to change it, insider action researchers take on responsibility for change as well as for research. IAR allows an inquiry into complex social events, such as NSD, in which actors construct and create meaning of their own environment and intervene accordingly with the aim to transform the system in which they operate (Coghlan and Brannick 2014). In this study IAR fulfils the purpose of generating data and facilitating a structured approach to creating actionable knowledge. As such IAR is suitable to address the research questions, to fully understand the social phenomena and processes relating to them. 


\section{Research Context and Initiative Selection}

The impact of power and politics on the development of new services and improving existing ones is explored in the context of a well-established, traditional and publicly funded university, which undertook several initiatives to generate independent income and to improve existing administrative services. For both types of initiative, the university's operations director (OD) was in charge who in turn nominated the first author (FA) to coordinate the initiatives on their behalf.

To generate new income streams the University's senior officers' group decided to investigate its potential to commercialise its assets and services raising independent income. The OD was nominated as sponsor for this initiative. The OD appointed the FA as Commercialisation Project Manager (CPM) and tasked her with exploring and implementing commercial opportunities on the OD's behalf. In parallel, the FA continued with her existing role of Operations Office Manager. As no formal support structures for commercial development initiatives were in place, the OD and FA had to design and implement them. This design challenge meant thinking about who would be selected to join a commercial initiative working group and contribute (what, how much, when), who would lead subinitiatives, and how to generate ideas and implement initiatives. They also had to develop an overall commercial strategy, decide how they would measure progress and success, and how they would embed the commercial structure in the overall university.

Together the OD and FA formed the Commercialisation Project Group (CPG), consisting of five senior members of the OD's management team. These were the Hospitality Director, the Library Director, the Communication Manager, the Facilities Manager and the Accounting Manager. In the university hierarchy, all members of this cross-functional group were more senior than the FA. This meant that she had no formal power to request collaboration. She had to rely on the OD's influence and her own ability to engender support.

For the purposes of this research, seven initiatives were chosen based on the following selection criteria:

- They had to be NSD initiatives

- They had to overlap in time and, so, had the potential to transfer the learning to subsequent initiatives

- One of the authors would be an actor in all initiatives, an insider action researcher

These selected initiatives are summarised in Table 1 . The FA was tasked with projectmanaging these initiatives. In brief, they were:

1) Café: Development and implementation of a new outdoor café.

2) Heritage: Exploiting a heritage trademark for merchandising opportunities.

3) Filming: Offering the university campus as a location to make movies.

4) Experiential: Developing and implementing new experiential services for tourists/visitors.

5) Emergency: Improving and implementing an emergency response plan.

6) Service Level: Developing and implementing a service level agreement.

7) Risk: Developing and implementing a risk management policy. 


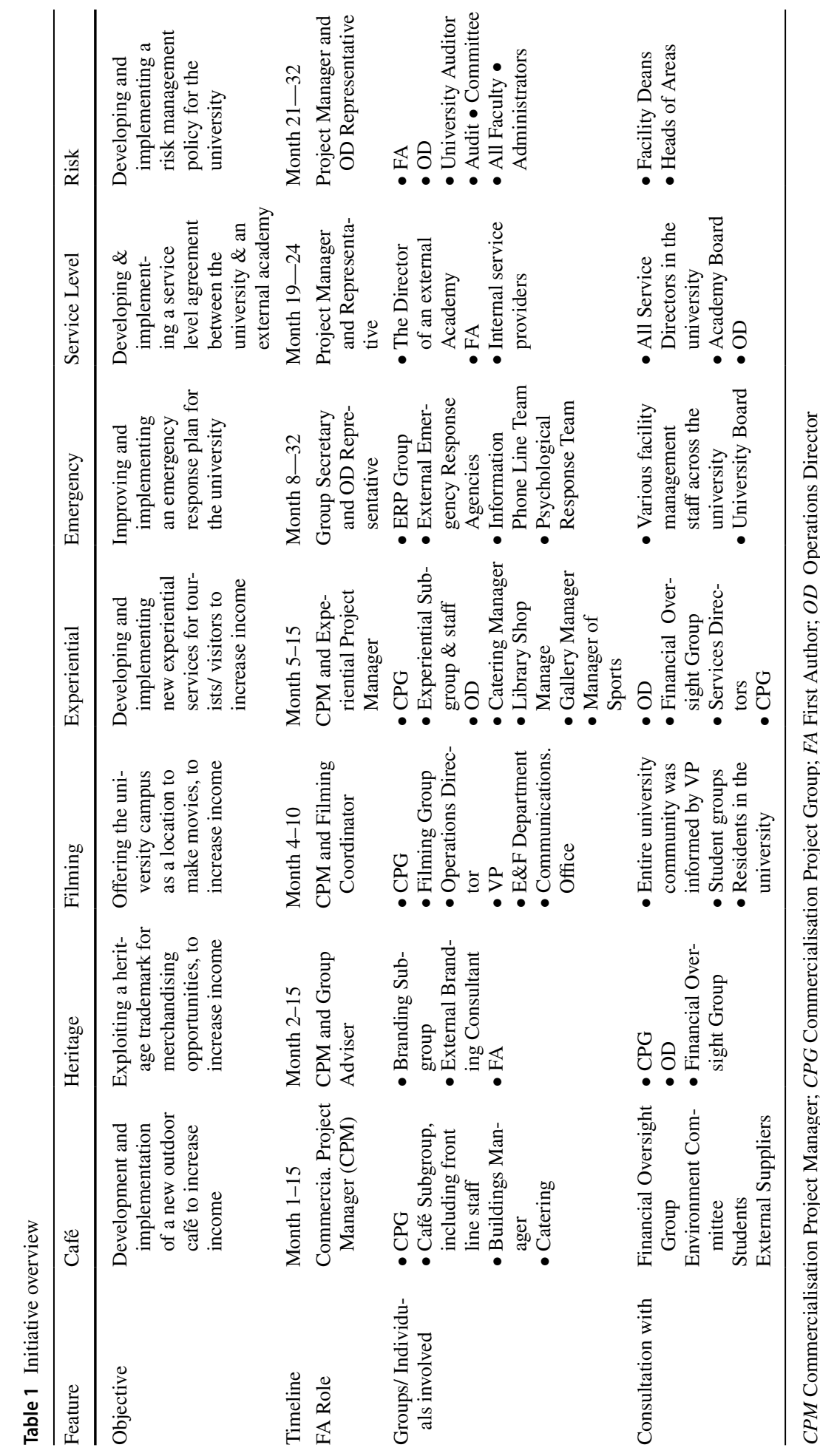




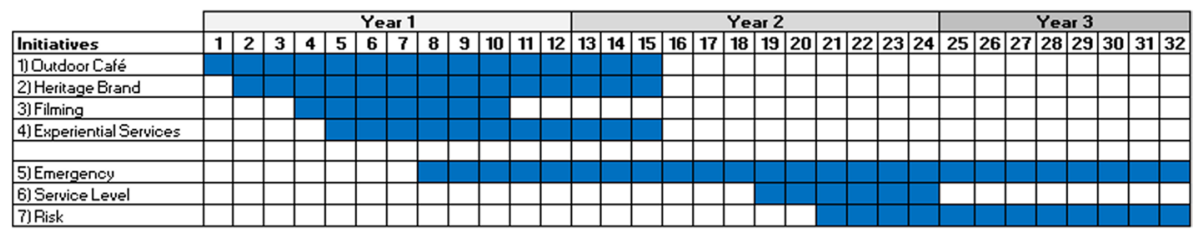

Fig. 3 The initiative timeline

As shown in Table 1 there was a working group for each initiative, consisting of administrative and professional staff, as the services concerned were all in the remit of the OD and not in the academic domain. The working groups usually met every second week, addressing agreed actions, provided updates on progress, discussed what worked well and what did not and agreed further actions. Even though the University's highest decisionmaking group had tasked the OD with sponsoring these NSD initiatives, many implementation barriers arose. Members of the university community applied power and political tactics to derail or stop the implementation process as further explained later in this study. The initiatives took place over a 32-month period, as illustrated in Fig. 3.

\section{Data Generation, Collection and Analysis}

Data were generated and gathered during the seven initiatives following the IAR cycle of constructing, planning, taking and evaluating action (Coghlan and Brannick 2014). The FA and co-workers/researchers took actions and recorded what happened in meeting notes. In addition, the FA recorded individual thoughts in a reflection log. She also conducted eight semi-structured interviews with internal and external service managers, about their service offerings and the barriers and enablers they encountered when developing them.

The data analysis phases are illustrated in Fig. 4, explaining the relationship between data generation and collection and the five phases of the data analysis undertaken in this work. In the first phase, data were put into different arrays, evidence was put into categories, data tables, flowcharts, mind maps and other graphics were created for examining the data. In the second phase, events were put in chronological order using timelines,

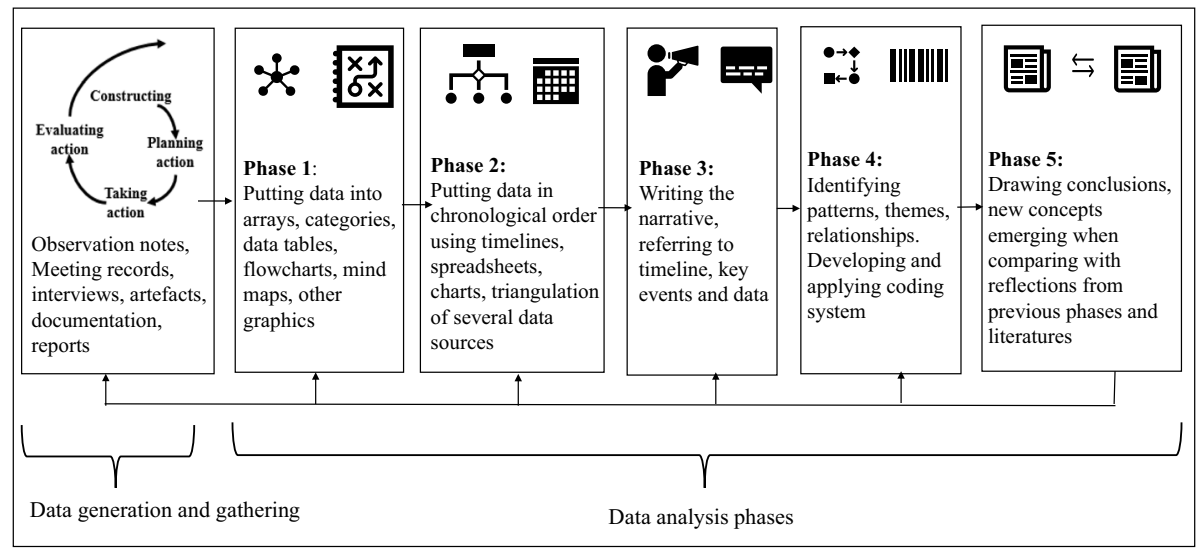

Fig. 4 Relationship between data generation, gathering and analysis 
spreadsheets and charts, referring to the initial data for confirmation and triangulation of several data sources. In the third phase, a narrative of the event sequence was composed, again referring to the data and timelines numerous times. In the fourth phase patterns and themes were noted, and contrasted between the initiatives, noting relationships between variables, identifying intervening variables. A coding system was developed and applied. In the fifth phase conclusions were drawn, new concepts to address the research question emerged by comparing the reflections from previous phases and literatures.

\section{Quality in Insider Action Research Projects}

As authors such as Susman and Evered (1978) suggest action research (AR) does not have to justify itself in relation to alternative epistemologies and research approaches, it must be justified within its own terms. There is reluctance to use the term validity in relation to AR, quality is preferred. Levin (2003) suggests four criteria for judging quality of AR: participation, real-life problems, joint-meaning construction and workable solutions:

- Participation means how well the IAR reflects cooperation between the researcher and the members of the system.

- Real-life problem means that the IAR intervention is guided by a concern in real life, practical outcomes and is governed by constant and iterative reflection as part of the process.

- Workable solution means that the insider action research projects result in significant work and sustainable outcomes.

- Joint meaning construction is the process of reflecting on and interpreting events, articulating meaning and generating an understanding as a collaborative process between the researcher and the members of the system. Of relevance is Coghlan and Brannick's (2014) use of Mezirow's (1991) three forms of reflection-content, process and premise-in an action research context.

- Content reflection is where the researchers, co-workers and associates think about the issues, what is happening.

- Process reflection is where they think about strategies, procedures and how things are being done.

- Premise reflection is where they critique underlying assumptions and perspectives (Why).

In action research, all three forms of reflection are critical and form the meta cycle of inquiry (Coghlan and Brannick 2014).

\section{Actions Taken, Outcomes, Learning and Reflection}

In this section we describe in detail three of the seven initiatives. We selected these initiatives, as they illustrate the scope of NSD activities, exploiting existing university resources and facilities for commercial purposes and by improving service processes. The first two describe initiatives aimed at generating non-exchequer income for the university. The third one describes a service process improvement. Each initiative description is structured in accordance with the action research cycle of constructing, planning action, taking action and evaluating action (Coghlan and Brannick 2014). As such, we first describe the context 
and purpose, then we illustrate the planning and implementation activities and finally evaluate and reflect on the initiatives' actions, outcome and our learning from action taken.

As the first author (FA) was tasked with project managing the NSD initiatives, the descriptions of each are written from a first-person perspective, to reflect her direct involvement.

\section{The First Commercial Initiative: The Outdoor Café}

In one of our early CPG meetings, the Hospitality Director reported that he had accidently met the Buildings Manager outside the Stone Building, a concrete building block built in the 1970s. They had talked about the empty space to the right of the main entrance. They both thought that the empty space would be ideal for an outdoor café. In the meeting, we discussed their idea and agreed that the benefits of opening an outdoor café would be twofold: the outdoor presence would increase visibility for the indoor catering facility and additional seating would increase income for the university. The Hospitality Director volunteered to lead the initiative, as he was the line manager for all the university's catering facilities and formed a café subgroup with his staff.

\section{Planning and Implementing}

We planned to have the Outdoor Café in place in time for the Easter vacation period. We expected that the influx of overseas visitors during the Easter holiday period would generate additional income which would demonstrate the value of commercial initiatives. Whilst the benefits of implementing new income sources were clear to us, the CPG members, a university committee raised concerns about possible negative effects of the Café. The Café subgroup halted the initiative, as they did not want to take a risk and implement the Café without a clear mandate by either the committee or the OD. On several occasions, it was uncertain who had the authority to decide for or against the Café. After the committee was satisfied that the Café would not damage the appearance of the surrounding buildings, the OD sent an email to all stakeholders, mandating the implementation of the initiative, "unless there are any showstoppers". After the mandate of the OD, the Cafe was installed over the period of three weeks, under the watchful eyes of many members of the university community. The Café subgroup assigned existing catering staff to service the outdoor cafe area, and many students, staff and visitors started using the new facility.

\section{Evaluating Action - Reflection on Operational Outcomes, Power and Politics}

We implemented the Café with a delay of one year from the original schedule, as we listened to and addressed concerns raised by the university community. For example, we faced issues relating to the university's formal decision-making structure and arguments about who would be the rightful decision maker. Many members of the university community complained to me about noise and the visual impact of the café. The "raison d'etre" of commercial initiatives was questioned by individuals, as commercial activities were not included in the university's mission of teaching and research. We dealt with each argument with different kinds of responses, for example keeping the Café persistently on meeting agendas, relentlessly communicating the benefits of independent university income, using the uncertainty surrounding this initiative and take actions in the absence of rules and policies, reframing the purpose of independent income as supporting the university's' mission 
of teaching and research. I had to take on different roles when trying to protect and push the initiative forward, while at the same time, accommodating concerns. These were for example conveying decisions from the OD and the university's senior decision-making forum, advising in financial and budget matters, pacifying irate members of the university community and gathering information from other universities and their commercial activities. A workable solution to a real-life problem was achieved i.e., a commercial income generating unit was implemented with participation of many actors. This means that the university now has a new income-generating outlet, which internal actors developed, applying internal existing resources only. This new outlet has a signalling function that the university is "open for business", and willing to use its underlying resources for commercial purposes, to address the shortage in funding.

\section{Reflection and Joint Meaning Construction}

During the course of the Café initiative, 24 CPG meetings took place over a period of 16 months during which the Hospitality Director reported back to the group on progress made. Each time we discussed what actions worked well and which actions had not been successful in driving forward the implementation of the initiative. The main content issues discussed were in relation to design issues, what to include in the business plan and when to open the Café. The main process issue was about achieving clarity on who would decide on the "go ahead" of the Café and what is needed to support the decision and who else we needed to communicate with. Premise reflection took place as we often talked about the difficulty with and mistrust of many university staff towards our group. We observed that there was a disparity between the espoused vision for commercialisation and income generation of the senior management and the actual support they provided to make the vision happen. We often commented on the lack of communication from the senior management team to the university community concerning the need to have additional commercial units such as the Café in place and we questioned ourselves on many occasions if we really had their support for the initiatives.

\section{Academia Meets Bollywood}

To generate commercial income, we, the CPG members, had made it known to the National Film Board that the university campus would be available as a location for filming. Shortly afterwards a well-known Indian film production company wanted to use the campus as a location for a major Bollywood movie that would be seen by more than 100 million people around the world. The university would be part of the script as the storyline included that the two heroes of the film, two major Indian film stars, were meant to be students at the University.

\section{Planning and Implementing}

Due to the complexity of the initiative, we established a filming subgroup to coordinate the location management, led by the communication manager. I joined the group as coordinator, to support the day-to-day location management. The project was sponsored by the Vice President (VP), as the movie would be seen internationally, potentially attracting large numbers of international students. There were concerns raised from both support service and academic staff, as it was felt that filming activities would negatively affect buildings, 
hinder building works and disturb students, staff and visitors living in campus accommodation. We addressed these concerns and for example changed filming schedules and ensured that additional support and security staff was on site. Each time concerns were conveyed to us, we debated and resolved how best to integrate the filming activity int the day-to-day university activity.

Then some filming dates clashed with critical university events such as the week and the weekend prior to term start when most students would drive onto the campus to move into their new rooms with their luggage. The accommodation manager raised the issue that visitors and residents of the university would complain about the noise and parking restrictions. A risk assessment and new insurance certificates had to be issued. Each time an issue arose we either met as a group, had conversations over the phone or quick face-to-face meetings to debate how best to facilitate the movie and overcome objections and obstacles. As the project coordinator, I spent a considerable amount of time explaining to concerned individuals why the filming initiative was important to the University.

The main dancing scene, typical for a Bollywood movie, attracted both positive comments and controversy. An additional day of filming had to be scheduled as it had rained during filming. The film producers suddenly decided that the dancers would dance on a different part of the university square. Unfortunately, no risk assessment had been carried out and the ground had not been checked for suitability. The Risk Assessment Manager was on-site to make sure that spectators were not injured. With this change, he was worried as the film crew had put cables everywhere on the footpath. As I was on site also observing the events, we discussed what could be done to continue the filming activity safely without endangering spectators. We concluded that we would keep a watchful eye on the dancers and divert the pedestrian traffic, so that nobody would trip over cables. We would include this sudden location shift in a "lessons learned" meeting after the event, to ensure incidents like this would not happen again. The Risk Assessment Manager volunteered to write a report for the OD. In the event, the dancing scene went off without a problem and was featured in national news, television and newspapers.

The film making created several temporary jobs which was generally viewed as positive, as the country at the time had to deal with a high unemployment rate. During the filming we developed a filming procedure, incorporating the learning from the Bollywood movie and providing guidelines for future filming initiatives. A week after filming was concluded the OD invited the filming subgroup, to evaluate the filming initiative.

\section{Evaluating Action-Reflection on Outcomes and Learning}

The operational outcome was that filming was completed on time, within existing resources, despite many issues arising. Based on our experience, we also developed a filming procedure which was applied to all future filming activities.

The university was mentioned in the story line of the movie which constituted considerable marketing value. Beside learning what it takes to carry out location management for a major movie we also learned what political tactics we must apply to ensure that the filming initiative was not derailed. It helped to engage with internal experts, having a strong, well reputed champion, frequently communicating the merits of the initiative to the university community, and collaborating with many stakeholders. Concerns were addressed swiftly and thoroughly, we welcomed suggestions and support. The post project evaluation was an important step, as it allowed all people involved to partake in learning for the future. 
Overall, we found a workable solution to a real-life problem, in collaboration with many stakeholders.

\section{Reflection and Joint Meaning Construction}

We reflected on Filming related issues during 16 CPG meetings as well as during Filming subgroup meetings. The content discussions were concerned with what building locations would be included, what insurance and legal issues should be covered. Process reflections were concerned with logistical issues such as the filming schedule and how we could work around the university calendar. The underlying premise discussions were about the rationale of causing major disruption to the university life when we would not generate additional income. As a Group we found eventual consensus that Filming "was here to stay". However, there were still strong objections from university staff. Working with the OD, we invited them to individual meetings, listened to their concern, but also endeavoured to convince them that this commercial initiative was necessary to secure the university's future.

\section{A Service Improving Initiative - Enhancing Emergency Responsiveness}

In addition to implementing income generating initiatives, I was also charged with coordinating service improvement initiatives, as part of my ongoing role as Operations Office Manager. One of the initiatives was to implement an emergency response plan. It is understood that universities can be subject to emergencies caused by disasters such as hostage situations and hazards such as fires. There had been a lot of press coverage about campus shootings in the USA and Germany at that time, so I envisaged I would get a lot of support for implementing emergency responses services and facilities.

\section{Planning and Implementing}

To begin, I formed an emergency planning subgroup consisting of seven university officers who had positions in the university that could support emergency planning (Table 1). The emergency planning responsibility had to be carried out on top of existing duties. In contrast to earlier initiatives, the efforts were "for the common good", i.e. of benefit for the entire university community, and was connected to the University's overall mission to care for staff, students, and visitors. As such, I received broad support from the subgroup. In our emergency subgroup's meetings, we debated what activities should be carried out if there was a serious emergency. For example, we had to decide where injured people should be treated, what crowd control measures to put in place, how and where to care for traumatised people, how to communicate should phonelines no longer work.

After four meetings, we agreed that a tabletop exercise would help to determine the level of emergency preparedness. A tabletop exercise is an activity in which key staff with assigned emergency management roles and responsibilities are gathered to discuss, in a non-threatening environment, various simulated emergencies. The exercise simulation was a hostage situation in one of the university buildings. All senior officers carrying decision making roles in an emergency took part in the exercise. The exercise highlighted issues that still needed to be resolved. For example, the subgroup had to put in place a dedicated telephone line and other means of communication in case of an emergency. The support teams had to be trained, lessons learned and further action items to be executed were documented. We carried out three further tabletop exercise and each time we discussed 
outcomes and alternative causes of action. For example, we put in place new emergency response measures such as casualty holding rooms and facilities to provide food and drink for people affected by disasters.

\section{Evaluating Action - Reflection on Operational Outcomes, Power and Politics}

The operational outcomes were that we had increased resilience, preparedness and capability to handle emergencies. A new emergency operational plan was approved by the University Board. We had found a workable solution to a real-life problem and many actors participated in the process of co-inquiry. As this project was a service improvement for the common good, we had not encountered as many adverse political tactics that needed to be addressed as in the commercial projects. We learned that an initiative that is beneficial for the university is easier to implement and raises less concerns.

\section{Reflection and Joint Meaning Construction}

In a number of Emergency subgroup meetings we discussed and made decisions regarding the content, the service system, for example which locations to include and what support teams to involve. Process issues concerning for example how to communicate when the phone lines were down, how to inform next of kin of emergency victims were discussed and decided also. The premise to protect lives and to prevent harm was given from the start, so meaning construction in this regard did not feature in meetings. However, a common question was how much resilience and ability to respond within was possible within given budgets and we often had to make difficult decision about what protective equipment could be purchased and installed.

\section{Results, Outcome Observations and Critical Reflection}

In this section we reflect on how formal and informal power dynamics and their application through political actions impacted the way the NSD initiatives progressed and their outcomes. Thereafter we critically reflect and evaluate the political enabling tactics that NSD actors applied to overcome this impact. Our reflections are summarised in the framework for managing power and politics in NSD (Fig. 5). The starting point was the initial research framework (Fig. 1) which is now informed by the research outcomes.

\section{Framework for Managing Power and Politics in NSD}

The initial research framework (Fig. 1) illustrated that NSD is impacted by power dynamics and political action that are drawn from both formal and informal power. Throughout the seven initiatives, we identified several political tactics that NSD actors applied. In the following sections we outline our observations and critical reflections that led to an enhanced framework, illustrated in Fig. 5. First, we address formal and informal power dynamics impacting NSD, thereafter we discuss the political tactics NSD actors applied to secure the implementation of new services. 


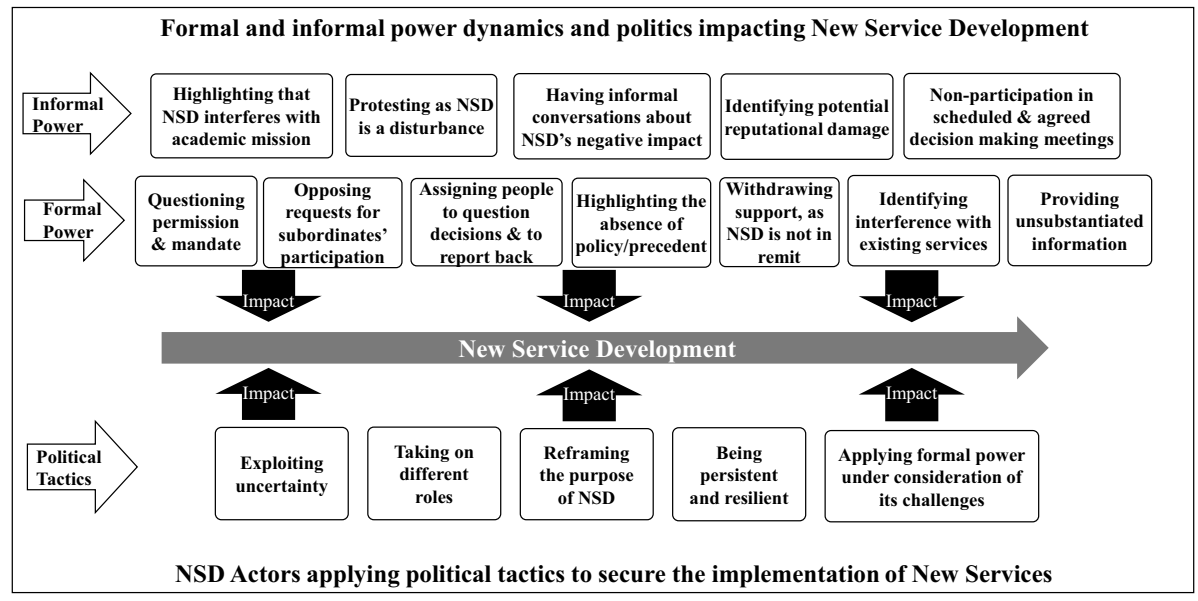

Fig. 5 Framework for managing power and politics in NSD

\section{Formal and Informal Power Dynamics Impacting NSD}

Existing knowledge highlights that formal and informal power dynamic may be applied to influence NSD.

Table 2 illustrates how formal and informal power execution impacted on NSD, what issues emerged as a result and what tactics NSD actors applied to address these issues advance NSD. The table also describes the impact and outcome of power applications and political tactics in all seven initiatives.

Formal power affecting NSD is shown for example as concerned service directors assigned their staff to the CPG, to question actions and report back planned actions for decision making and to delay progress (Experiential). During the Café project many individuals worried about the highly visible planned installation. It would interfere with the academic mission of the university and it would impact on the iconic beauty of the surrounding buildings. Individuals asked representatives of estate committees to object to the Café plans. Others raised their concerns directly as members of university committees and decision-making fora. Even though the OD had deemed the Café as a viable option to generate commercial income, their power (and by extension that of the FA and the Commercialisation Group) derived from their formal role as OD was not accepted. Endeavours to generate commercial income conflicted with the University's mission.

As illustrated in Table 2, power dynamics and political action based on formal power were:

- Questioning permission and mandate (Café)

- Opposing requests for subordinates' participation (Experiential)

- Assigning people to question decisions and to report back on plans (Experiential, Heritage)

- Highlighting the absence of policy/precedent (Café, Experiential, Service Level)

- Withdrawing support, as NSD is not in remit (All commercial initiatives)

- Identifying interference with existing processes and services (Café, Filming)

- Providing unsubstantiated information (Experiential, Heritage) 


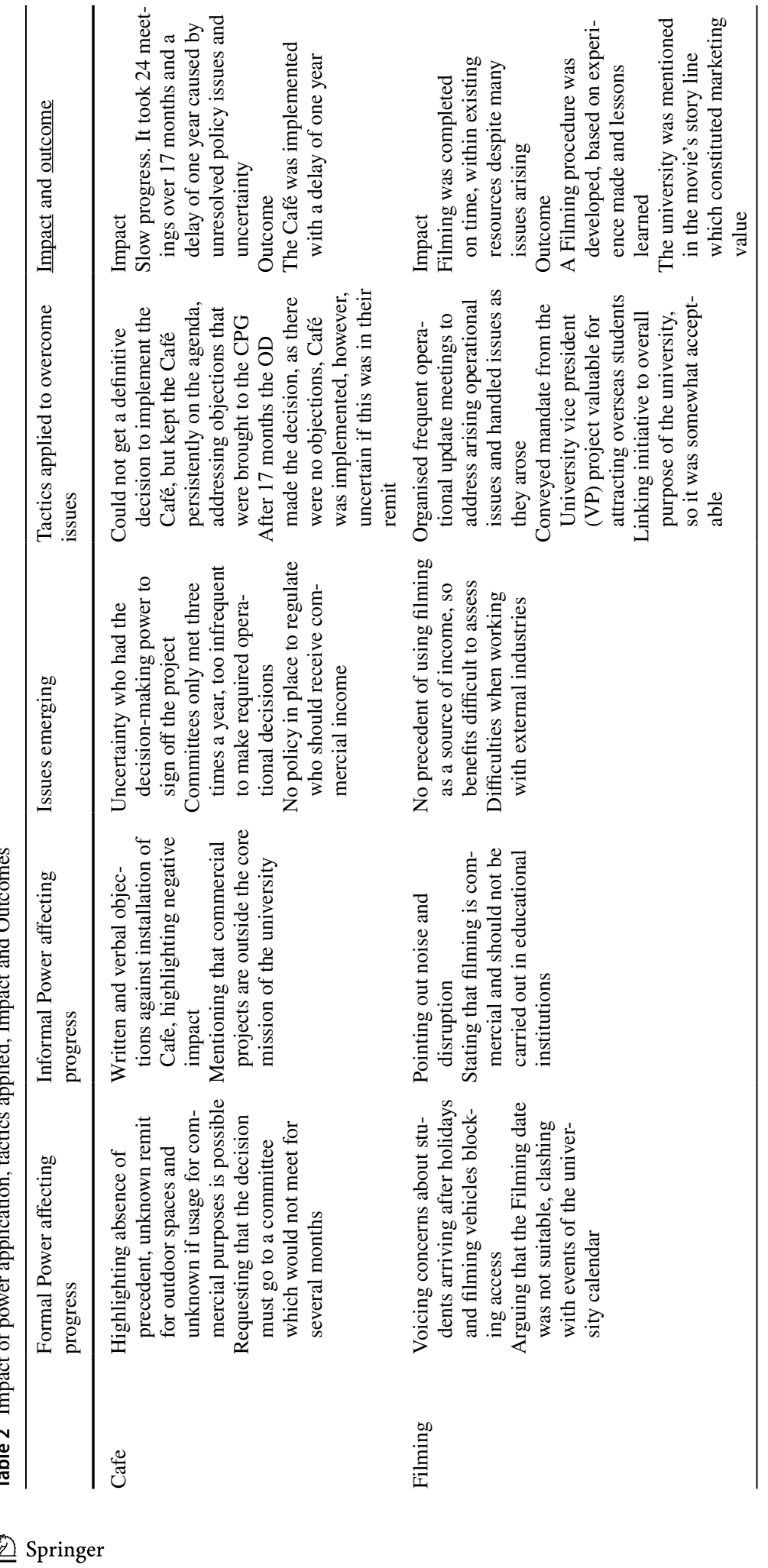




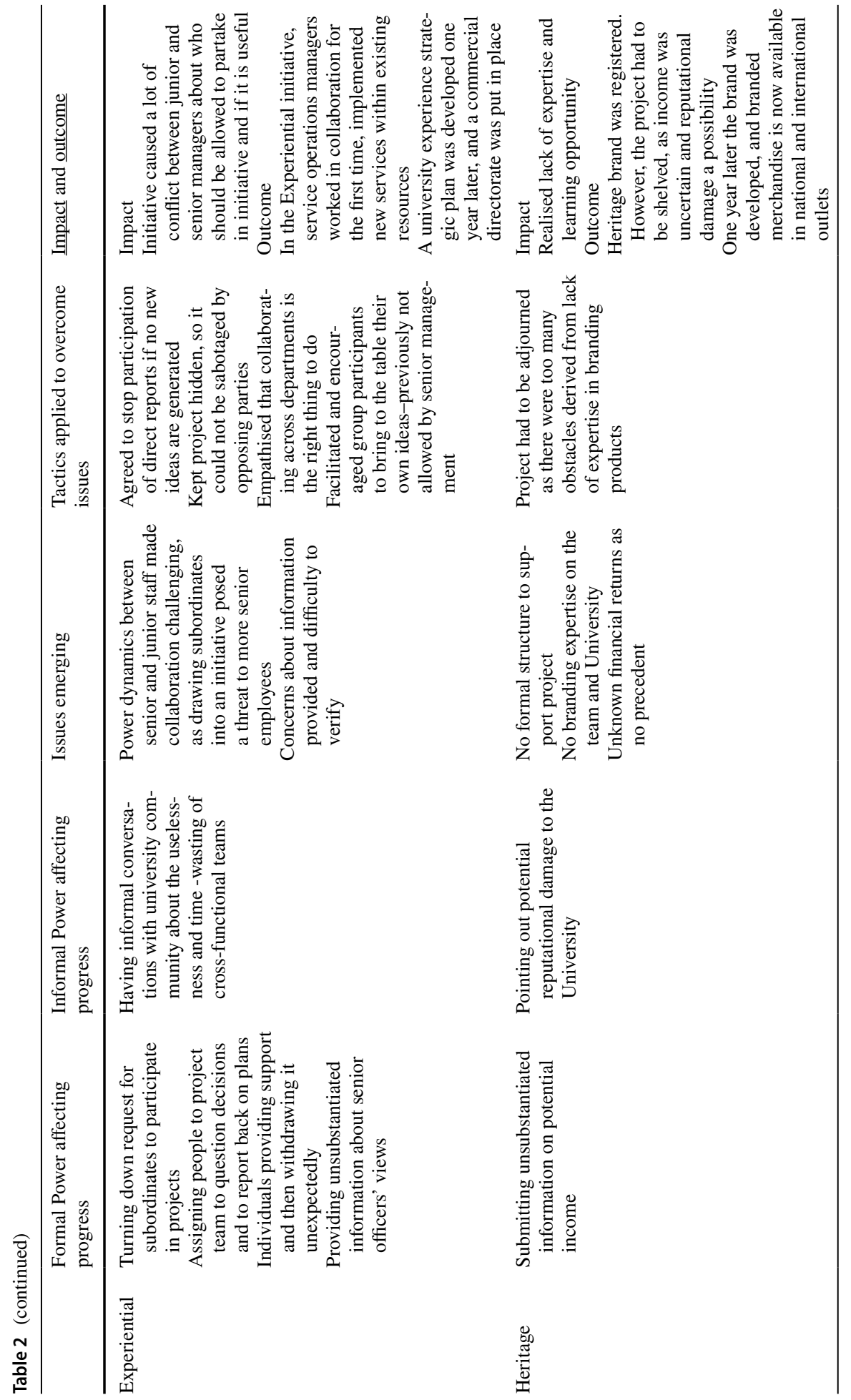




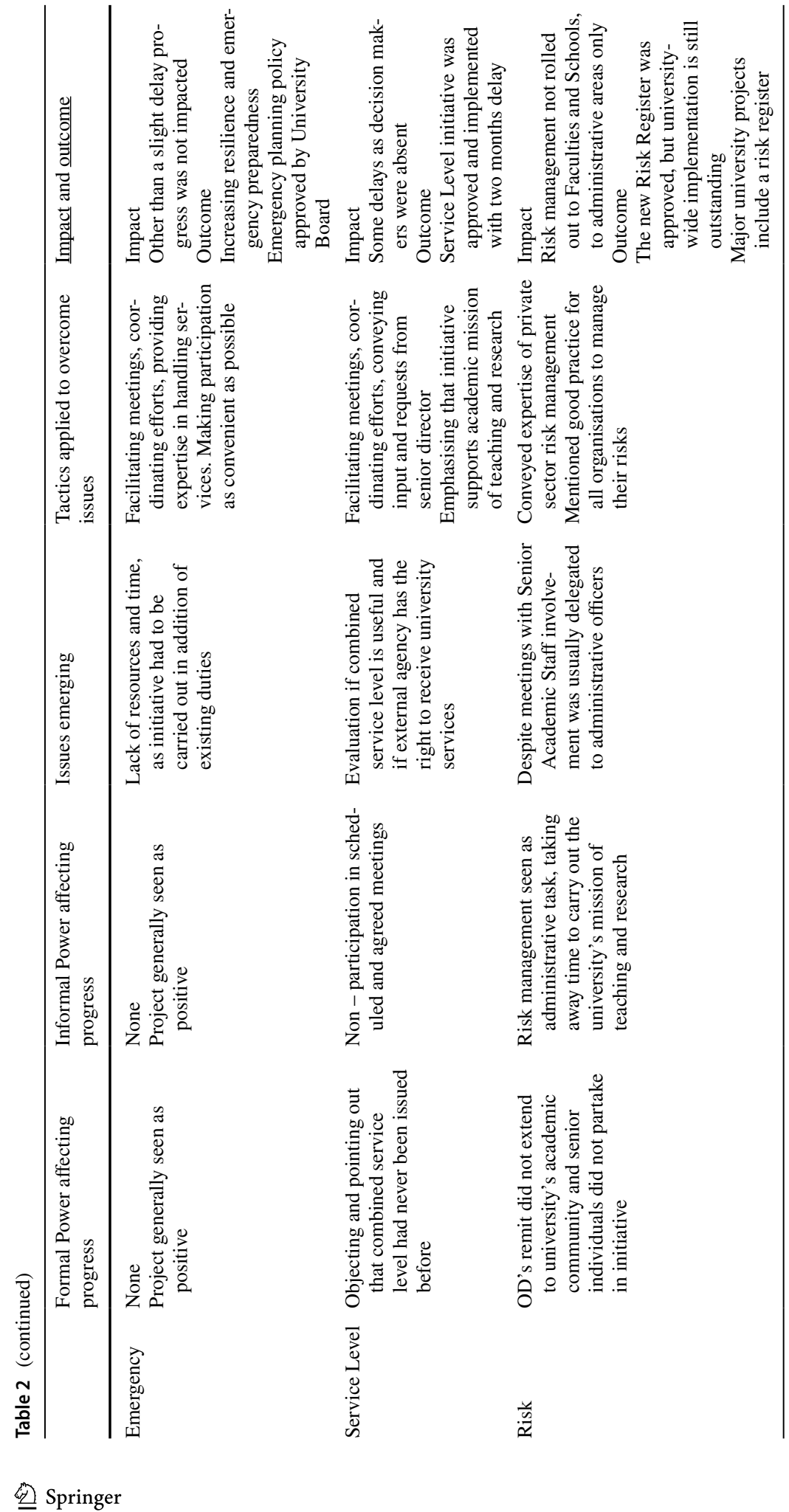


Table 2 also illustrates power dynamics and political action based on informal power. These were not based on a formal role held in the university, but based on informal networks and communication channels:

- Highlighting that NSD interferes with the academic mission (Café, Filming)

- Protesting against NSD as a disturbance (Café, Filming)

- Having informal conversations about NSD's negative impact (Experiential)

- Identifying potential reputational damages of NSD (Heritage)

- Not participating in scheduled and agreed decision making meetings (Service Level)

The next section in the framework explains the political tactics NSD actors applied to achieve NSD.

\section{Political Tactics to Secure the Development of New Services}

Based on analysis and reflection of the seven NSD initiatives (Table 2) this section illustrates the political tactics NSD actors applied in order to overcome adverse political actions. These were:

- Exploiting uncertainty (All projects)

- Taking on different roles (All projects)

- Reframing the purpose of NSD (Café, Filming, Experiential, Heritage)

- Being persistent and resilient (All projects)

- Applying formal power under consideration of its challenges (Café, Filming, Experiential, Heritage)

These tactics are further analysed in the following sections.

\section{Exploiting Uncertainty}

As the commercial and service improvement initiatives had no precedent and there was no relatable policy in place there was uncertainty in relation to several things, as Table 3 illustrates. Strategies to exploit uncertainty for the benefit of new service implementation were assuming agreement in the absence of disagreement, repurposing, extending permission, adjourning, caring, testing and assisting.

It appears that uncertainty was an enabling factor in overcoming oppositional formal and informal power application. In the Service Level initiative for example where a combined service level agreement was to be developed for the first time, we received objections from service managers who would be responsible for supplying the service. We highlighted that the implementation would benefit the university's academic mission of teaching and research and would test the implementation in the academy. "If it doesn't work, we'll undo it." Or as Mintzberg (1979, p 362) said: "Power is, after all, gained at the locus of uncertainty”. So, exploiting uncertainty may be a useful political tactic in the repertoire of university managers who are tasked with NSD and perhaps other change initiatives. 


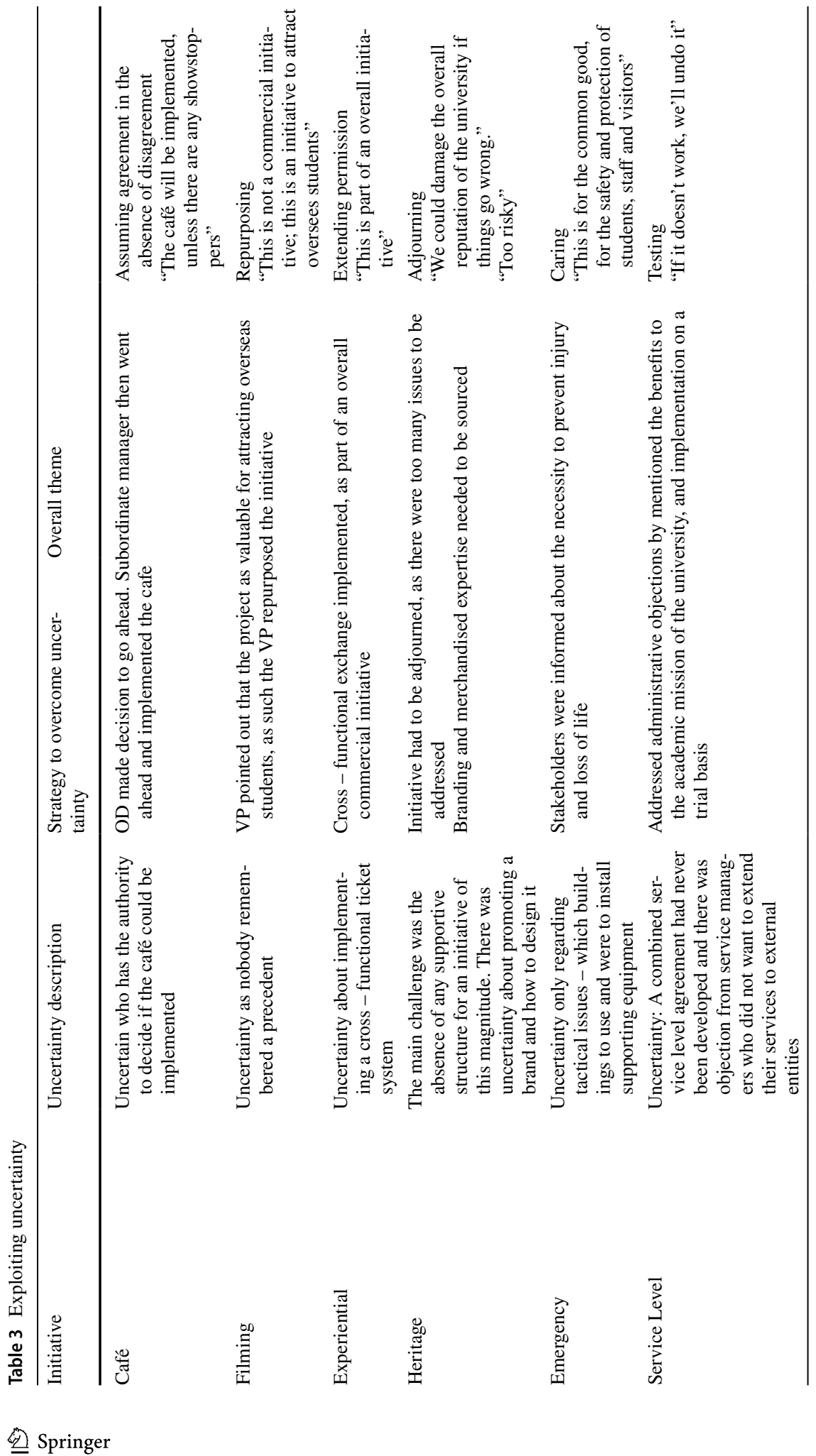




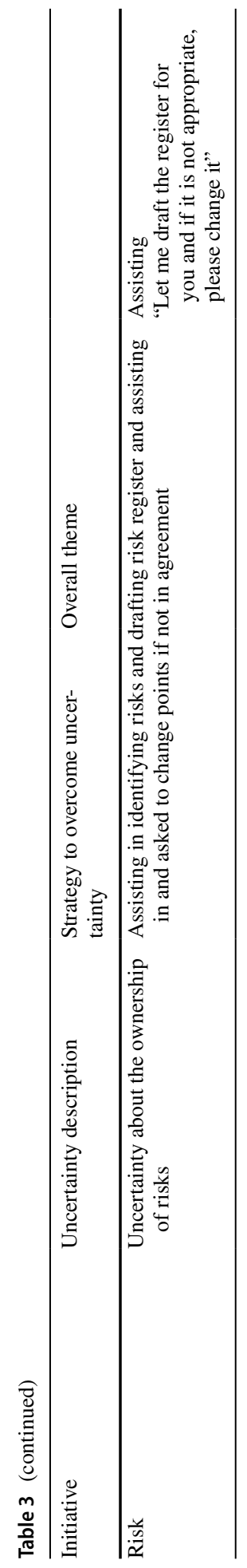




\section{Taking on Different Roles}

Roles are building blocks of a social system in terms of position and requirements and are socially constructed (Katz and Kahn 1966). Playing different roles to implement change is referred to as being a political entrepreneur by authors such as Buchanan and Badham (2008) and Coghlan and Brannick (2014). In order to facilitate the development of new services and ensure the implementation of the new projects, the FA took on different (unofficial) roles to facilitate service development. Table 4 illustrates the roles she played for each initiative.

We discuss each of these roles in turn:

- As Facilitator, she facilitated meetings, information exchanges and discussions, coordinated efforts as Group Secretary (Emergency, Risk).

- As Adviser, she advised in financial and budget matters (Café, Filming, Experiential)

- Her role as Conveyer included conveying information to and from the HD, the OD, and the Planning Group (All initiatives).

- As Legitimiser and OD Representative she defended the Project Groups and their actions (All initiatives).

- As Pacifier she addressed concerns about NSD projects (Café, Filming).

- As Gatekeeper she provided information available from external companies, universities, and companies (Filming, Experiential, Emergency).

- Finally, as an insider action researcher, she reflected on her actions and that of the group on her own (first person) and with the working groups (second person) and linked these reflections to existing knowledge.

The roles the FA applied to successfully implement new services had the character of collaboration and support, rather than a hierarchical or formal character.

\section{Reframing the Purpose of NSD}

As the NSD actors had learned that initiatives would gain more support when the purpose was for the university's common good (For example the Emergency initiative, protecting the lives of students, staff and visitors), actors would emphasise the common good in all projects. The purpose of commercial projects would usually be to generate income, which was considered as being contrary to the institution's mission. The "common good" purpose was to support the university's primary mission of teaching and research (e.g. Café and Filming). Funds could be spent to implement enhanced student welfare services, such as Student Health and Counselling Services.

\section{Being Persistent and Resilient}

As the initiatives' reflections indicate, persistence in combination with resilience enabled the NSD actors/co -researchers to progress NSD. They kept NSD initiatives relentlessly on the agenda, to be further explored. This phenomenon is illustrated for example in the Café initiative. It took 24 meetings over 17 months to be implemented. The uncertainty 


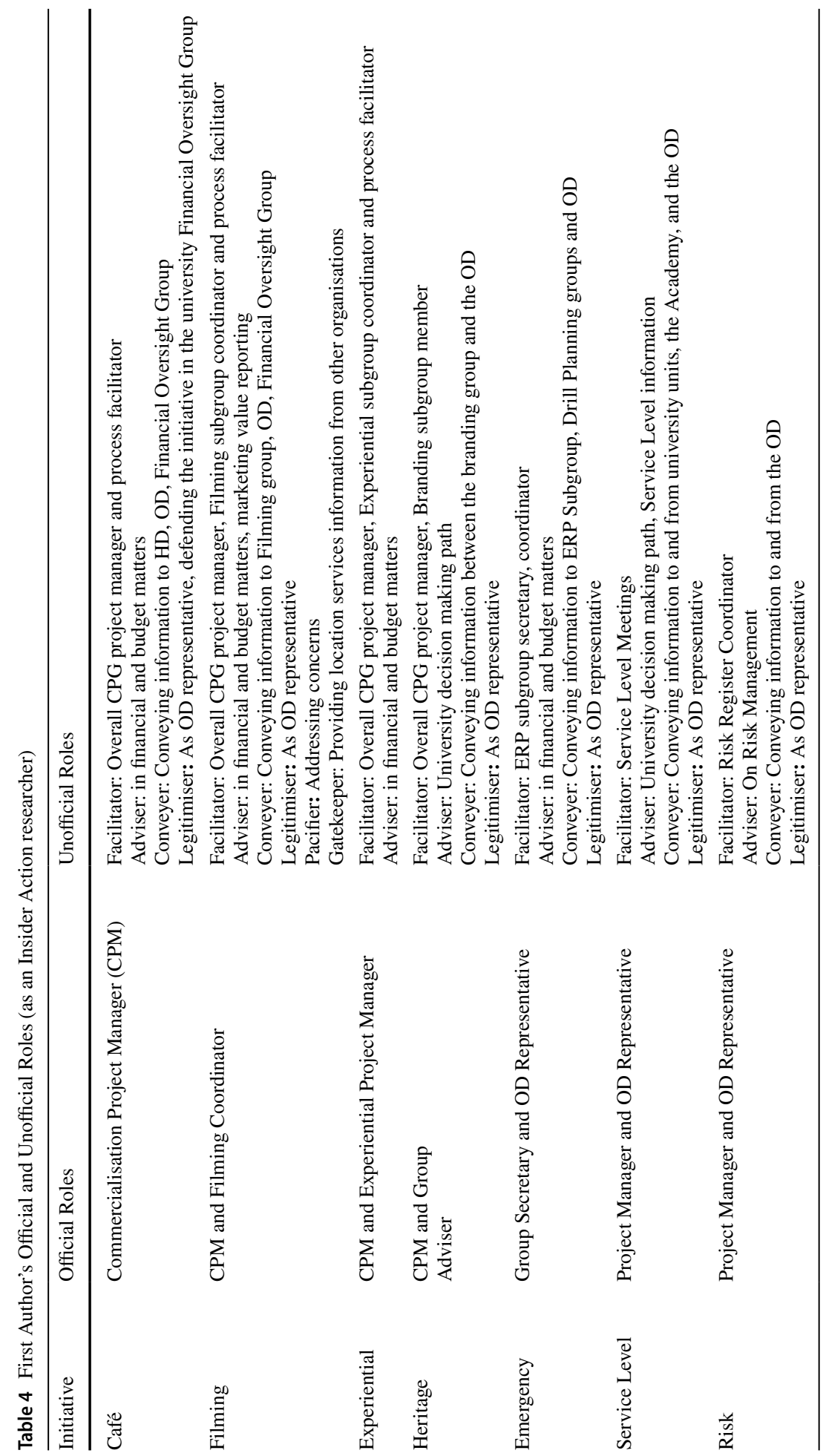


surrounding novel NSD projects helped NSD actors to persistently make a case for exploring the benefits and feasibility of NSD further, as there was no rule nor policy not to do so.

Resilience also helped to deal with setbacks. Many individuals opposed the Cafe initiative and NSD actors had to address all concerns in a respectful, considerate, and creative way. The ability to confidently handle challenging situations and conflicting views was tested in the Filming, Experiential and Heritage initiatives also.

\section{Application of Formal Power Under Consideration of its Challenges}

Her position as CPM and manager of the OD Office gave the FA access to privileged information. As the OD wanted the initiatives to succeed, all subordinates were asked to support the initiatives also. This helped the FA to gain espoused support, which was not always identical with real support. In the commercial initiatives Café, Filming, Experiential and Heritage some service managers had been asked by the OD to partake and contribute to the initiatives. At progress meetings though it became apparent that hardly any progress was made, and other day-to-day operational matters had taken priority. Therefore, the application of formal power, whilst helping to gain initial support such as assigning staff to project teams and access to information, may not be enough to carry NSD initiatives through to implementation, without the application of political skill and tactics.

\section{Reflection on Research Quality and the Value of IAR}

In drawing conclusions from these reflections, the four action research quality criteria cited by Levin (2003) are applied.

- Was there participation between the researcher and the members of the system? Yes: As Table 1 shows, in each NSD project several service managers and other stakeholders participated as full members in the NSD teams, as co-researchers and NSD actors. In addition, many other stakeholders throughout the NSD process were consulted.

- Was a real-life problem addressed? Yes: Each NSD initiative was part of the university's endeavour to generate income through NSD and improve existing services.

- Were workable solutions found that are significant and sustainable? Yes: The NSD actors found sustainable solutions for all seven initiatives. They had to "adjourn" one project to a later time outside the research timeline, Heritage. A year later, however, with having a dedicated full-time team in place, Heritage was implemented. All initiatives are significant to the university as they either contribute to the non-exchequer university or improved existing services to internal and external customers. They are sustainable as they have become permanent features, supported by dedicated staff and facilities.

- Were initiatives jointly evaluated? Yes: As part of each initiative, the working groups assembled a working group to plan, carried out actions and reflected on their actions and outcomes, for example in post-project reviews. NSD actors learned from their experiences and applied what they learned to later initiatives. Applying Mezirow's (1991) three forms of reflection for each initiative indicates the joint evaluation and joint assessment to arrive at a workable solution. 
Meeting Levin's quality criteria illustrate that this insider action research project is good quality research. It addresses the research questions how power and politics impact NSD and what NSD actors through political tactics can do to achieve NSD, building on Smith and Fischbacher-Smith (2005) and Börjesson and Elmquist (2011). IAR was chosen to address these questions and it uncovered several details in relation to political tactics (e.g. uncertainty exploitation) that cannot be revealed with positivist research methodologies, for example identifying data emerging because of an intervention, gaining an understanding of emerging phenomena and contingent emerging factors, identifying linkages and identifying why these relationships exist (Coughlan and Coghlan 2002).

IAR also adds value for the described university, the insider action researcher and other individuals involved, as it facilitates learning and capability development which would not have happened with other research methodologies either.

\section{Summary and Conclusion}

This research work seeks to advance the understanding how power and politics affect NSD in publicly funded university setting. It informs a field of practice which needs to respond quickly to dramatic changes in its environment. In this study, formal and informal sources of power and how power and politics affect the implementation of new services in the publicly funded university are critically evaluated. In the research we took an initial research framework and developed it further to arrive at the framework for managing power and politics in NSD.

Political tactics applied by NSD actors to secure the implementation of new services were investigated. The first one was that of exploiting uncertainty (Table 3). Mintzberg (1989) Buchanan and Badham (2008) acknowledge that any type of change creates uncertainty and that this uncertainty can generate room to manoeuvre. In this study we support and add to their assertion by illustrating in detail what political tactics NSD actors can apply in order to use uncertainty and facilitate NSD. Strategies to exploit uncertainty for the benefit of new service implementation included assuming agreement, repurposing, extending permission, adjourning, caring, testing, and assisting.

The second political tactic is that of taking on different roles (Table 4). Buchanan and Badham (2008) declare that actors engage in role taking and switching in change processes. Coghlan and Brannick (2014) pointed out that an insider action researcher must deal with the issue of role duality. Role duality is referred to when managers augment their organisational role with that of the researcher. We enhance the authors' arguments by identifying further roles particular to NSD (Facilitator, Adviser, Conveyer, Legitimiser, Pacifier, Gatekeeper and Insider Action Researcher) and in what circumstances the roles are taken up.

Further political tactics identified are that of, reframing the purpose of NSD, being persistent and resilient, and applying formal power under consideration of its challenges.

Several formal and informal power dynamics and politics impacted on NSD. However, instead of looking at these political tensions as barriers that need to be overcome by political tactics to secure NSD implementation, they could also be seen as surfacing/discovering contradictions or paradoxes. Actors should acknowledge and engage with these contradiction - i.e. make them explicit and as such enable not only individual but also organisational learning. (Vince et al. 2018). As such this research provides an example for the value of IAR for individual and organisational capability enhancement. 
Seven insider initiatives illustrated the advancement and implementation of novel services and how individual actors overcame the challenge by applying political tactics. A limitation of this IAR study is that only one well- established, traditional research university in the public sector was researched. Newer, more modern universities may have a different approach to implementing NSD and it remains to be tested if the framework for managing power and politics in NSD is applicable in other contexts. However, other universities in similar circumstances may find our evaluation and reflection useful. Secondly, the research does not explain how external factors such as the input from external actors and the economic environment affect NSD within the researched university directly, only by proxy, through the interpretation of internal NSD actors. As such, external factors are constructed by the actors in the system.

This research focuses on NSD initiatives in the non-academic domain of a university. Further research might investigate how NSD in the academic domain may require different approaches to the application of power and politics.

\section{Funding Open Access funding provided by the IReL Consortium}

Open Access This article is licensed under a Creative Commons Attribution 4.0 International License, which permits use, sharing, adaptation, distribution and reproduction in any medium or format, as long as you give appropriate credit to the original author(s) and the source, provide a link to the Creative Commons licence, and indicate if changes were made. The images or other third party material in this article are included in the article's Creative Commons licence, unless indicated otherwise in a credit line to the material. If material is not included in the article's Creative Commons licence and your intended use is not permitted by statutory regulation or exceeds the permitted use, you will need to obtain permission directly from the copyright holder. To view a copy of this licence, visit http://creativecommons.org/licenses/by/4.0/.

\section{References}

Allen RW, Madison DL, Porter LW, Renwick PA, Mayes BT (1979) Organizational politcs, tactics, and characteristics of its actors California. Manag Rev 22:77-83

Baines T, Bigdeli AZ, Bustinza OF, Guang Shi V, Baldwin J, Ridgway K (2017) Servitization: revisiting the state-of-the-art and research priorities. Int. J. Oper. Prod. Manag. 37:256-278

Börjesson S, Elmquist M (2011) Developing Innovation Capabilities: A Longitudinal Study of a Pr.oject at Volvo Cars. Creat Innov Manag 20:171-184. https://doi.org/10.1111/j.1467-8691.2011.00605.x

Buchanan D, Badham R (2008) Power, politics and organizational change: winning the turf game. Sage, London

Coghlan D (2001) Insider Action Research Projects: Implications for Practising Managers Management Learning 31

Coghlan D, Brannick T (2014) Doing Action Research in your own Organisation. Sage, London, UK

Coughlan P, Coghlan D (2002) Action research for operations management. Int J Oper Prod Manag 22:220-240

Davies JL (2001) The Emergence of Entrepreneurial Cultures in European Universities Higher Education Management 13

den Hertog P, van der Aa W, de Jong MW (2010) Capabilities for managing service innovation: towards a conceptual framework. J Serv Manag 21:490-514. https://doi.org/10.1108/09564231011066123

Denneen J, Dretler T (2012) The financially sustainable university. Bain and Company

Ferris G, Treadway D, Perrewé P, Brouer R, Douglas C, Lux S (2007) Political Skill in Organizations. J Manag 33:290-320

Hartley J, Alford J, Hughes O, Yates S (2015) Public value and political astuteness in the work of public managers: the art of the possible. Public Adm 93:195-211 
Johnson SP, Menor LJ, Roth AV, Chase RB (2000) A critical evaluation of the new service development process. In: Fitzsimmons JA, Fitzsimmons MJ (eds) New service development: Creating memorable experiences. Sage Publications, Thousand Oaks, CA

Katz D, Kahn RL (1966) The Social Psychology of Organizations. Wiley, New York

Levin M (2003) Action Research and the Research Community. Concepts and Transformation 8:275-280

Mezirow J (1991) Transformative Dimensions of Adult Learning. Jossey-Bass, San Francisco, CA

Mintzberg H (1989) Mintzberg on Management: Inside Our Strange World of Organizations. The Free Press, New York

Papke Shields K, Malhotra MK (2008) Manufacturing managers' perceptions of functional power in manufacturing organizations. Int J Oper Prod Manag 28:858-874

Pfeffer J (1992) Understanding Power in Organisations California Management Review Winter:29-50

Richards S (ed) (2006) New public policy paradigm - new leadership Action Learning. Leadership and Organizational Development in Public Services, Routledge, London

Santos JB, Spring M (2013) New service development: managing the dynamic between services and operations resources. Int J Oper Prod Manag 33:800-827. https://doi.org/10.1108/IJOPM-12-2012-0559

Smith A, Fischbacher-Smith M (2005) New service development: A stakeholder perspective European J Mark 39 https://doi.org/10.1108/03090560510610707

Susman G, Evered R (1978) An assessment of the scientific mertis of action research. Adm Sci Q 23:582-603

Van de Ven A, Poole MS (1995) Explaining development and change in organizations. Acad Manage Rev 20:510-540

Vince R, Abbey G, Langenhan M, Bell D (2018) Finding critical action learning through paradox: The role of action learning in the suppression and stimulation of critical reflection. Manag Learn 49:86-106. https://doi.org/10.1177/1350507617706832

Publisher's Note Springer Nature remains neutral with regard to jurisdictional claims in published maps and institutional affiliations. 